Article

\title{
Applying Airborne LiDAR to Map Salt Marsh Inland Boundaries
}

\author{
Lee B. van Ardenne (D) and Gail L. Chmura * (D)
}

Citation: van Ardenne, L.B.; Chmura, G.L. Applying Airborne LiDAR to Map Salt Marsh Inland Boundaries. Remote Sens. 2021, 13, 4245. https://doi.org/10.3390/ rs13214245

Academic Editor: Deepak R. Mishra

Received: 30 August 2021

Accepted: 14 October 2021

Published: 22 October 202

Publisher's Note: MDPI stays neutral with regard to jurisdictional claims in published maps and institutional affiliations.

Copyright: (c) 2021 by the authors. Licensee MDPI, Basel, Switzerland. This article is an open access article distributed under the terms and conditions of the Creative Commons Attribution (CC BY) license (https:// creativecommons.org/licenses/by/ $4.0 /)$.
Department of Geography, McGill University, 805 Sherbrooke St W, Montreal, QC H3A 0B9, Canada; lee.vanardenne@hotmail.ca

* Correspondence: gail.chmura@mcgill.ca

\begin{abstract}
The determination of rates and stocks of carbon storage in salt marshes, as well as their protection, require that we know where they and their boundaries are. Marsh boundaries are conventionally mapped through recognition of plant communities using aerial photography or satellite imagery. We examined the possibility of substituting the use of $1 \mathrm{~m}$ resolution LiDAR-derived digital elevation models (DEMs) and tidal elevations to establish salt marsh upper boundaries on the New Brunswick coasts of the Gulf of St. Lawrence and the Bay of Fundy, testing this method at tidal ranges from $\leq 2$ to $\geq 4 \mathrm{~m}$. LiDAR-mapped marsh boundaries were verified with high spatial resolution satellite imagery and a subset through field mapping of the upland marsh edge based upon vegetation and soil characteristics, recording the edge location and elevation with a Differential Geographic Positioning System. The results show that the use of high-resolution LiDAR and tidal elevation data can successfully map the upper boundary of salt marshes without the need to first map plant species. The marsh map area resulting from our mapping was $\sim 30 \%$ lower than that in the province's aerial-photograph-based maps. However, the difference was not primarily due to the location of the upper marsh boundaries but more so because of the exclusion of mudflats and large creeks (features that are not valued as carbon sinks) using the LiDAR method that are often mapped as marsh areas in the provincial maps. Despite some minor limitations, the development of DEMs derived from LiDAR can be applied to update and correct existing salt marsh maps along extensive sections of coastlines in less time than required to manually trace from imagery. This is vital information for governments and NGOs seeking to conserve these environments, as accurate mapping of the location and area of these ecosystems is a necessary basis for conservation prioritization indices.
\end{abstract}

Keywords: blue carbon; tidal marsh limits; DEM; Gulf of St. Lawrence; Bay of Fundy

\section{Introduction}

Salt marshes, lands vegetated by grasses and other plants and flooded by tidal water, provide a wide range of ecosystem services. Owners of waterfront property benefit from salt marsh frontage as it protects their property by dissipating the energy of storm waves [1-3]. Their shallow waters also provide nurseries for anadromous fish, such as salmon smolt, that, as they migrate to sea, need protection from larger predators [4]. The most recently recognized ecosystem service provided by salt marshes is their function as one of the world's most efficient carbon sinks, branded as blue carbon [5]. Through photosynthesis, their vegetation takes carbon dioxide from the atmosphere and stores much of it as organic matter in its roots. The slow rate of decomposition in the wet, salty marsh soil means that the carbon stays there for millennia, and their rate of carbon sequestration is an order of magnitude more rapid than in terrestrial forest soils [6].

These ecosystems, however, have been subjected to significant losses of area over time due to land use change and other anthropogenic disturbances [7]. Furthermore, the increasing rate that the sea level rises threatens the long-term permanence of these 
ecosystems on many coasts. These ongoing losses have prompted rising interest in the conservation of these ecosystems [8], but their conservation requires that we be able to accurately identify and map them. Furthermore, key information on marsh ecosystem services, such as the rates and total stock of carbon storage in salt marshes, requires accurate maps of these ecosystems [5,9].

Comprehensive regional mapping of salt marshes in North America was underway at least as early as 1960 in locations such as Maine [10]. Those earliest mapping efforts were based on aerial photography with field verification [10]. The implementation of regulations to protect salt marshes required accurate delineation of upper boundaries, which were determined by identifying the location where marsh vegetation transitioned to upland vegetation, e.g., [11]. The ability to discriminate the critical species required color, preferably color infrared, aerial photographs at a suitable scale, such as 1:1000, but the aerial photo interpretation often required field verification [11]. More recently, vegetation mapping has been made possible with satellite imagery but delineation of fine-scale features, such as wetland boundaries, requires similarly high-resolution imagery along with extensive field verification. This can prove problematic, as many marshes can be difficult to access, and it becomes difficult and costly to perform effective field verification when large-scale mapping of marshes is needed.

The elevation of the marsh boundary at which marsh vegetation transitions to upland vegetation and the elevation range of a salt marsh are determined by the height of tidal flooding and will thus be consistent among marshes along a section of coastline with similar hydrography and the same pool of plant species [12-14]. (This is because tolerance to submergence and salinity varies with species (e.g., [15]), and salt marshes generally have distinct vegetation zones delineated by elevation relative to the local tidal range.) Therefore, we can use LiDAR (Light Detection and Ranging) data, which allows the determination of surface elevations remotely at sub-meter precision, to help map salt marsh characteristics, as they are generally restricted to a certain elevation range relative to the tide.

Although LiDAR is not available for all coastlines [9], where it is available, it has been extensively used to map various features in coastal habitats, including salt marshes. Digital surface models (DSMs) and digital elevation models (DEMs) derived from LiDAR data have been used to map features in and around salt marshes and other wetlands (most often used in conjunction with multi/hyperspectral imagery). The features include: habitat area [16-20]; vegetation heights [20]; invasive species spread [21]; tidal creek networks [22]; and estimation of aboveground biomass and carbon stocks [20,23]. LiDAR data in conjunction with Landsat imagery have been used to estimate the future area available for marsh inland migration in response to the rising sea level [24].

However, problems with using LiDAR data in salt marshes have been reported. Due to the high density of salt marsh vegetation, which can create dense mats of organic material, sometimes dozens of centimeters thick, LiDAR can fail to receive true ground returns in salt marshes [25-27]. This results in the elevations of the marsh surface indicated by the LiDAR data being higher than they should be. In comparison to RTK GNSS points in marshes, vertical LiDAR offsets of $15 \mathrm{~cm}$ and higher can occur [25]. Seasonal variability of marsh vegetation height over the growing season and the collapse of vegetation into a mat due to the senescence of marsh vegetation near the end of the growing season can make elevation offsets vary over time [27]. As such, mapping of salt marsh area using LiDAR must account for this possible offset to maintain accuracy.

Despite these offsets, with high point density $\left(\geq 4\right.$ points per $\left.\mathrm{m}^{2}\right)$ and some ground control to filter or adjust the elevations, LiDAR has been demonstrated to be a robust tool for producing DEMs in single salt marshes to model the available area [25,26]. Thus, hydrographic data (e.g., highest astronomical tide and mean water level), in tandem with LiDAR data, can potentially be used to delineate the upper boundary of tidal marshes over extended lengths of a coastline without the need to map vegetation directly. In turn, the use of satellite imagery to assist in mapping marsh boundaries may not be required beyond visual quality control. The high-precision work of filtering and correction of LiDAR 
point clouds to produce DEMs to account for the elevation offset are not practical to map multiple marshes over a long coastline due to the processing time required to do so with many congruous LiDAR point clouds. Furthermore, LiDAR flights for large stretches of coastline can be performed over several months and on several different years, which may cause notable differences in the vertical vegetation offsets that would need to be applied. A simpler method may be to adjust tidal data using regional offsets developed for sections of a coastline using those modified values in conjunction with LiDAR-derived DEMs to approximate the marsh area. We test this method in this study.

To determine if the mapping of inland salt marsh boundaries could be successful without high-resolution imagery and extensive field verification, we examined the application of LiDAR-derived DEMs and hydrographic data to establish salt marsh boundaries and areas on the coasts of the province of New Brunswick (NB), Canada. Because the province's coastlines border both the Gulf of St. Lawrence and the Bay of Fundy, we had the opportunity to test this method in tidal ranges from $<2 \mathrm{~m}$ to $12 \mathrm{~m}$. We verified marsh boundaries through comparison to satellite imagery and field visits. During the latter, we were able to correct for LiDAR vegetation offsets and mapping errors. We then compared our maps to those of the province, prepared using aerial photogrammetry.

\section{Materials and Methods}

\subsection{Study Sites}

This study involved mapping the salt marshes of the entire coastline of NB, Canada (Figure 1). This amounts to an area of $\sim 12,827$ ha based upon current provincial salt marsh mapping. Marshes along the coast of the Bay of Fundy have tidal ranges $>4 \mathrm{~m}$ ), while marshes on the Gulf of St. Lawrence coastline generally have tidal ranges $\leq 2 \mathrm{~m}$. This leads to differences in the elevation range over which marshes exist.

The marshes of the region have similar vegetation that is generally categorized into three zones. The marsh fringe, the transition between terrestrial vegetation and the marsh, contains a combination of the plant species Spartina pectinata, Juncus gerardii and Juncus balticus, with occasional Bolboschoenus maritimus. The high marsh, the central region of the marsh and often the largest vegetation zone, is vegetated primarily by Spartina patens. Spartina alterniflora dominates the low marsh at the seaward edge, as well as the banks of tidal channels.

Twelve marshes served as validation sites for the elevation of the marsh upland border (Figure 1, Table 1) out of a pre-selection of 20.

\subsection{LiDAR and Hydrographic Data}

We acquired $1 \mathrm{~m}$ resolution LiDAR-derived DEMs of the entire NB coastline from GeoNB [28]. The LiDAR was acquired in the summer and fall (June-October) of 2016 through 2018. The LiDAR data utilize the CGVD2013 vertical datum. The LiDAR data were collected using a Riegl Q680i at an average flying height of $1100 \mathrm{~m}$. Horizontal data accuracy is reported as $0.30 \mathrm{~m}$, while vertical accuracy is reported as $0.115 \mathrm{~m}$ root mean square error for non-vegetated surfaces. The DEMs are $10 \times 10 \mathrm{~km}$ tiles. The DEM was via the TIN of the bare ground and model key point LiDAR point classes, upon which the final $1 \mathrm{~m}$ resolution DEM was interpolated using the natural neighbors sampling.

Tidal elevations for the coast, including the Highest Astronomical Tide (HAT), Highest High Water Large Tide (HHWLT), Highest High Water Mean Tide (HHWMT), Mean High Water (MHW), Mean Water Level (MWL) and Chart Datum (CD), were acquired from the Canadian Hydrographic Service (CHS) (see Table 2 for tide level definitions). The tidal elevation values were converted from chart datum to CGVD2013 to render them compatible with the DEMs. The tidal data were in the form of a point file (shapefile format) which gave estimates for these values along both coastlines. We also used data from the 29 tidal stations on the Gulf of St. Lawrence coast and 26 on the Bay of Fundy for further validation. 


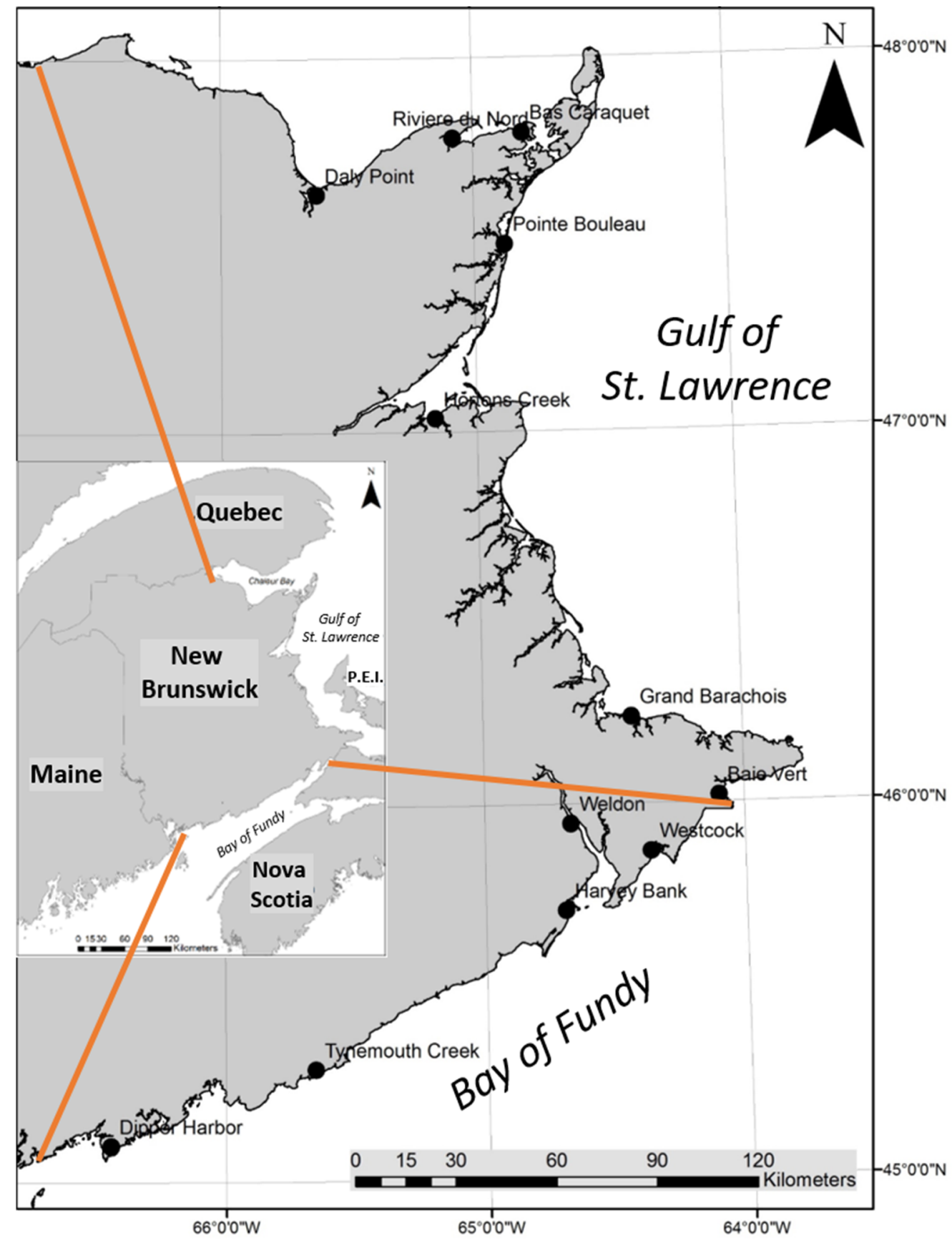

Figure 1. Inset: location map of New Brunswick, Canada. Orange lines indicate the two coastlines on the Bay of Fundy and Gulf of St. Lawrence. Verification sites are named and position indicated.

\subsection{Field Data}

We selected marsh sites for field verification based upon the following criteria: representative sections of coastline; lack of hydrological restrictions (which could affect marsh expanse within the tidal frame); natural upland edge present (e.g., avoiding fill, cleared vegetation, adjacent development); and accessibility. Based upon these criteria, we selected 13 sites depicted in the map in Figure 1. At each site, we strove to locate a section with minimal freshwater influence. There are no salt-tolerant trees or shrubs in NB, and unless inland areas have been cleared, this arboreal vegetation occurs just at the upper edge of a salt marsh. Thus, we chose that vegetation as our indicator of the terrestrial/salt marsh border and positioned transects to include such vegetation wherever possible. 
Table 1. Verification sites with elevation offsets between GNSS survey points and DEM elevations at those locations. Differences between the provincial and new polygons are reported along with the size ratio.

\begin{tabular}{|c|c|c|c|c|c|c|c|}
\hline Marsh & $\begin{array}{l}\text { Average Marsh } \\
\text { Terrestrial Edge } \\
\text { GPS Elevation } \\
\text { (m, CGVD2013) }\end{array}$ & $\begin{array}{l}\text { Average Marsh } \\
\text { Terrestrial Edge } \\
\text { LiDAR Elevation } \\
\text { (m, CGVD2013) }\end{array}$ & $\begin{array}{l}\text { Elevation } \\
\text { Offset (m) }\end{array}$ & $\begin{array}{c}\text { Provincial } \\
\text { Polygon Area } \\
\left(\mathrm{m}^{2}\right)\end{array}$ & $\begin{array}{c}\text { New Polygon } \\
\text { Area }\left(\mathrm{m}^{2}\right)\end{array}$ & $\begin{array}{l}\text { Difference } \\
\qquad\left(\mathrm{m}^{2}\right)\end{array}$ & $\begin{array}{c}\text { New Provincial } \\
\text { Polygon Area } \\
\text { Ratio }\end{array}$ \\
\hline Baie Verte & 0.79 & 0.83 & 0.04 & $1,397,327$ & 937,224 & 460,103 & 0.67 \\
\hline Bas-Caraquet & 4.45 & 4.45 & 0.00 & 723,671 & 662,625 & 61,046 & 0.92 \\
\hline Daly Point & 0.99 & 1.36 & 0.36 & 289,958 & 262,311 & 27,648 & 0.90 \\
\hline Dipper Harbour & 6.87 & 7.25 & 0.38 & 169,595 & 156,266 & 13,329 & 0.92 \\
\hline Grand Barachois & 0.92 & 1.08 & 0.16 & 179,932 & 195,889 & $-15,957$ & 1.09 \\
\hline Harvey Bank & 0.32 & 0.58 & 0.26 & 353,007 & 317,259 & 35,747 & 0.90 \\
\hline Hortons Creek ${ }^{\ddagger}$ & 6.18 & 5.98 & -0.21 & 268,678 & 416,838 & $-148,160$ & 1.55 \\
\hline Pointe Bouleau & 3.58 & 3.26 & -0.32 & 57,267 & 36,711 & 20,556 & 0.64 \\
\hline Riviere du Nord & 6.09 & 6.62 & 0.53 & 143,475 & 96,322 & 47,153 & 0.67 \\
\hline Tynemouth Creek & 0.59 & 0.86 & 0.27 & 104,130 & 90,807 & 13,323 & 0.87 \\
\hline Weldon & 0.39 & 0.72 & 0.33 & $1,393,269$ & $1,499,162$ & $-105,893$ & 1.08 \\
\hline Westcock ${ }^{\boxplus}$ & 1.09 & 1.21 & 0.12 & $1,320,687$ & N/A & N/A & $\mathrm{N} / \mathrm{A}$ \\
\hline Mean & - & - & 0.16 & - & - & - & 0.87 \\
\hline St. Dev & - & - & 0.25 & - & - & - & 0.16 \\
\hline
\end{tabular}

${ }^{ }$Fluvial marsh with river channel mapped in the DEM as the same elevation as the marsh surface. The area is thus larger than it should be, and this site is excluded when calculating the mean ratio. " ${ }^{\mathrm{L}} \mathrm{LiDAR}$ in region mapped tidal channels separating marshes as the same elevation as the marsh surface, causing separate marshes to be mapped as one large complex. Marsh area mapping in the region using LiDAR was thus considered unreliable, and the difference was not calculated.

Table 2. Tide level definitions.

\section{Tide Level}

Highest Astronomical Tide (HAT)

Highest High Water Large Tide (HHWLT)

Highest High Water Mean Tide (HHWMT)

Mean High Water (MHW)

Mean Water Level (MWL)
Definition

The highest tidal elevation recorded for a location over the last 19-year tidal nodal cycle.

The mean of the highest yearly high waster levels recorded for each of the 19 years in the last 19-year tidal nodal cycle.

The mean of all of the highest daily water levels recorded for each of the 19 years in the last 19-year tidal nodal cycle.

The mean of all high water levels (lower and higher) for each day in the 19-year tidal nodal cycle.

The mean of all hourly tide elevations recorded at a site over the available period of record.

A reference plane that designates the elevation that water will rarely, if ever, go below under normal meteorological conditions. In tidal systems, this is often close to the mean of the lowest daily tide levels throughout the year.

Chart Datum (CD)

At each marsh, we determined its upland edge based upon vegetation and soil characteristics. We then measured the location and elevation of the edge with a GNSS receiver in RTK mode (Sokkia GRX2). The vertical accuracy of the GNSS receiver is reported as $15 \mathrm{~mm}+1$ ppm with a horizontal accuracy of $10 \mathrm{~mm}+1 \mathrm{ppm}$. These measurements provided a reference for visual corrections to the marsh borders using satellite imagery. The height of the litter and tallest vegetation were also recorded to determine if those values explained discrepancies between the GNSS elevations and the LiDAR elevations. Between 8-16 points were taken at each validation site once the manual upland delineation was completed.

Where possible, GNSS points for each site were tied into a provincial benchmark. The Precise Point Positioning (PPP) tool, available from Natural Resources Canada [29], was used to post-process GNSS base data at sites where a benchmark was not available and was also used for sites with benchmarks for comparison. At most validation sites, one or more points were taken in open flat areas (e.g., a road surface) to provide a bare ground reference point. This served as a control and assisted in the comparison of DPGS points to those of the LiDAR DEMs. Each bare ground point was used to produce an elevation offset between the point and the corresponding DEM pixel it overlay, which was then applied to 
all other points at the site. The resulting elevations were then compared to the elevations given from either correcting the points to a benchmark or PPP post-processing results.

\subsection{Marsh Border Extraction}

Due to the large area being analyzed, marsh area extraction was performed per DEM tile $(10 \times 10 \mathrm{~km})$ along the NB coastline. Satellite imagery, including Planet Scope imagery ( $3 \mathrm{~m}$ pixel size), Google Earth imagery and base maps available in ArcGIS, were used to assess the accuracy of the mapping. Older Google Earth and ArcGIS basemaps were useful in some areas because marshes in the region have not changed significantly in the last decade, barring occasional anthropogenic disturbance of sites. All mapping and analyses were performed using ArcGIS 10.7.1. The workflow of the analysis is shown in Figure 2.
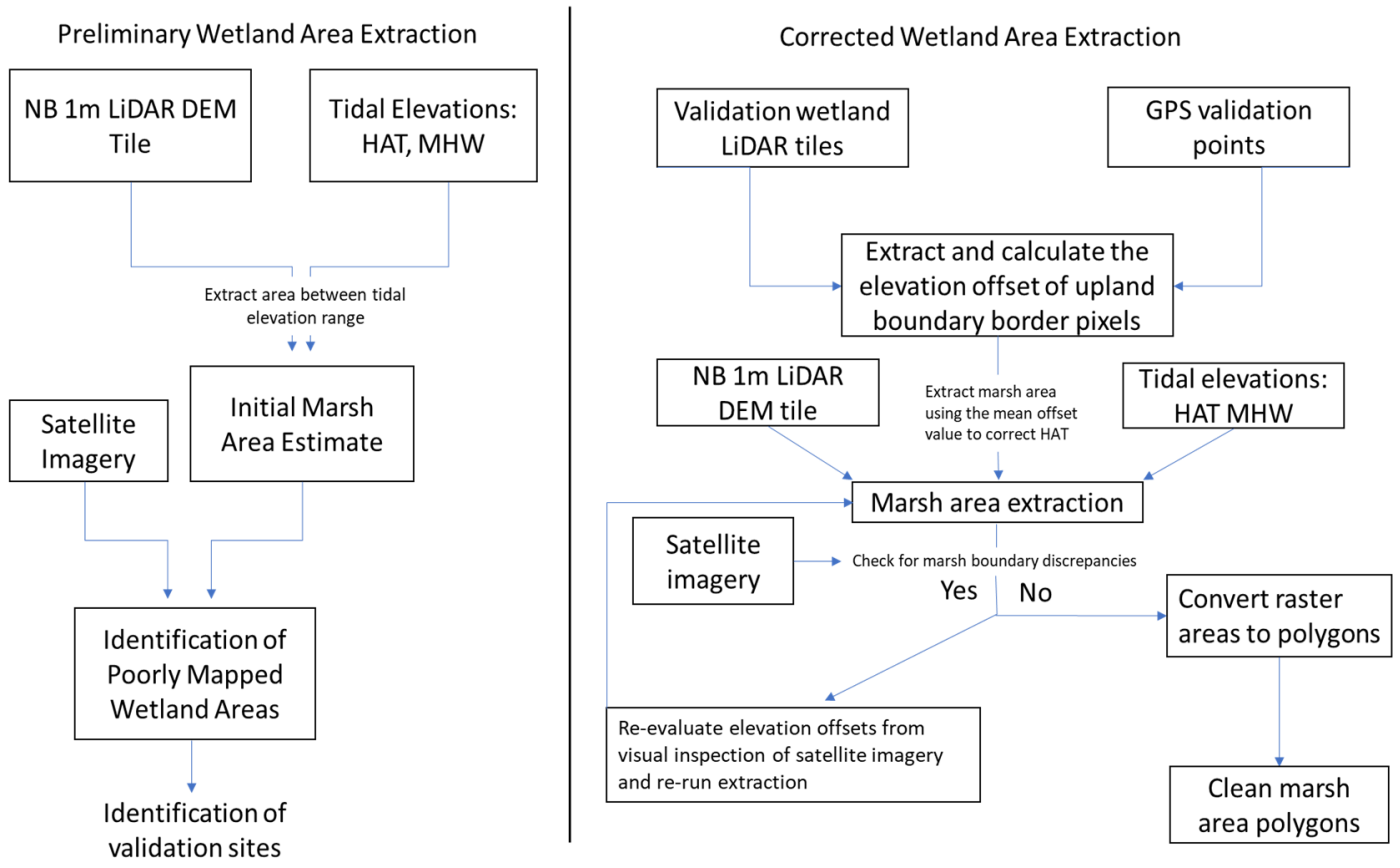

Figure 2. Flowcharts showing the analysis workflow of the preliminary (left) and corrected wetland area extraction (right).

Initial estimates of the marsh borders were created by extracting the DEM pixels whose elevations fell between the HAT and MWL (corresponding to the upper and lower marsh bounds, respectively). Extractions for each DEM tile were performed using the average of HAT and MHW point cloud values corresponding to the section of the coast covered by each DEM tile. This was considered acceptable from a quality perspective as the difference in the tidal range from one end of a $10 \times 10 \mathrm{~km}$ DEM was less than the vertical error of the DEMs. In some rare cases, where a single DEM tile contained marshes that were subjected to a large difference in tide ranges due to local topography, the DEMs were sectioned so that each subsection had a consistent tidal range.

The extracted pixels represent the initial estimate of the marsh area. This marsh area estimate was overlain on satellite imagery and manually investigated for any significant deviation from what was visible in the imagery. Areas where DEM pixels were extracted in unusual areas (e.g., in the middle of a large tidal channel, open ocean or over forested areas) or not present in areas that were clearly marsh in the satellite imagery were noted. These poorly mapped locations represented various mixtures of errors in the base LiDAR data, incorrect tidal data or unusual/poor LiDAR point density over water. The identification of errors in the location of marsh borders was used to inform the choice of verification sites.

The mean difference between the GNSS points delineating the upland marsh edge and the corresponding pixels they overlay was calculated for each validation marsh. These values considered the combination of the vegetation offset common to salt marshes and the 
LiDAR vertical error. Extractions were re-run for each validation site to check if the upper bounds of the extracted DEM pixels matched the horizontal position of the GNSS points. Using the mean of the offset values of all validation sites, the upper bounds of each DEM tile extraction were adjusted. In the case of further mapping errors (i.e., forest mapped as marsh due to too high of an upper boundary elevation estimate), values from individual validation sites rather than the mean were tried until the best match was found.

In cases where it did not match with satellite imagery, the elevation of the lower bounds of each extraction was modified from the MWL by overlaying satellite imagery over the DEMs and selecting a sample of DEM pixels adjacent to the marsh-sea boundary from which an elevation was estimated. Slight changes to that elevation were then performed on a trial-and-error basis until the lower bounds matched marsh edges on satellite imagery. This was possible because the visual difference between the marsh lower limit and open water/mudflat is generally very distinct. After adjustment and re-extraction, the resulting extracted pixels were converted from raster to vector format prior to manual cleaning.

\subsection{Cleaning and Correction}

The extraction of the marsh area from LiDAR results in several unavoidable artifacts, which require manual cleaning of the final polygons. First, as the LiDAR mapping method used in this study extracts all DEM pixels that fall within the elevation range of the salt marshes, it results in the extraction of a narrow band of pixels (typically 1-3 m wide) along nearly the entire coastline that when changed from raster to polygon produce a narrow polygon that traces the coast. Even in terrain too steep or too exposed to wave erosion to support salt marsh development, there will be a narrow band that falls within the elevation range of salt marsh. The narrow "coastal" polygon interlinks with nearly all the salt marshes along the coast, effectively turning most of the coastline into a series of large polygons. This would result in the overestimation of the salt marsh area. These narrow bands were manually clipped from the vector layer by removing the areas between wetlands using satellite imagery to determine the point at which they connected with legitimate marsh polygons.

"Terrestrial" areas within the LiDAR DEM tiles that fall within the elevation range were also extracted. The most obvious case of this effect is dyked lands (former salt marsh cut off from tidal influence by an anthropogenic barrier), where the land located on the terrestrial side of the dykes exists at an elevation equal to or lower than that of the marsh on the seaward side. When mapped, all dyked land is also extracted, with only the narrow dyke area separating the contemporary marsh from the terrestrial interior. These areas also were removed.

Other than large contiguous areas such as dyke land, there were many small (5-15 $\left.\mathrm{m}^{2}\right)$ areas separated from the marsh by patches of higher ground. These can be close enough together that they interlink with each other and the main marsh polygon resulting in a "messy" upland limit when the extracted raster is converted to a polygon vector layer. Some marshes had thousands of such tiny polygons surrounding the upland. Many of these small polygons were removed by instituting a minimum mapping unit of $5 \mathrm{~m}^{2}$ in size; however, some of the larger or interlinked patches had to be deleted manually as they were of a size equal to some legitimate marsh polygons. These small polygons can add up to a considerable area, necessitating their removal to ensure the salt marsh area was accurately represented.

\section{Results}

\subsection{Trial Mapping Phase}

During the initial trial mapping phase (using the HAT and MWL as the upper and lower bounds for extraction), we found that some of the marsh boundaries derived from the LiDAR DEMs, particularly those on the Gulf of St. Lawrence coast, related poorly to the marsh boundaries suggested by satellite imagery. In some cases, the lowest section of the marsh surface derived from the LiDAR data was above the HHWLT reported for the region, 
resulting in the extraction of little to no marsh area. The lower bounds also tended to vary between marshes, tending to be closer to MHW in macrotidal environments and MWL in microtidal systems. We suspected that the dense vegetation and litter found in many marshes would result in the LiDAR DEMs overestimating ground elevation; however, the extent to which the marsh area was underestimated in the some regions was greater than expected. A comparison of adjacent DEM tiles where marshes were marsh area appeared to be well mapped versus those where no marsh area was mapped, indicating that the tiles had comparable elevation levels of both terrestrial and marsh surfaces. A comparison of the tidal point clouds over the same area, however, indicated that the tidal data showed very large variations in value over the same distance. This indicated a problem with the tidal dataset due to a low density of tidal stations for some sections of the NB coastline.

This issue affected the entire coastline between Shediac Bay and Baie Verte, requiring that the mean of GNSS field validation point elevations for the region be used to estimate the upland marsh limits for all DEM tiles on that coastline. Much like the lower bounds, the upper bounds were then adjusted slightly if any significant mismatch between the extracted DEM pixels and the satellite imagery marsh area was found, according to the type of mismatch (i.e., overestimate or underestimate). This was necessary as not using tidal elevations as the base estimate means that elevations would not be adjusted for tidal variations along the coast.

\subsection{GNSS Elevation Offsets}

The mean LiDAR DEM elevations extracted at upland limits were $0.16 \pm 0.25 \mathrm{~m}$ higher than the mean elevations recorded by the corresponding GNSS points. Overall, most GNSS elevation calibration methods (the use of a provincial benchmark, PPP on base station data or a point located on flat unvegetated ground to adjust GNSS points to the DEM elevation) agreed within $\pm 0.04 \mathrm{~m}$ in marshes where all were performed. An exception was a benchmark we excluded because it had values that diverged more than $0.3 \mathrm{~m}$ from either the PPP or bare ground estimates (which themselves agreed within $0.03 \mathrm{~m}$ ). In all cases, we used the GNSS elevation that produced the smallest difference from the extracted DEM elevations for each site. Two sites had GNSS points higher than the LiDAR DEM elevations. When we excluded them, the mean offset became $0.25 \pm 0.17 \mathrm{~m}$ higher than the mean GNSS elevations. We assume these discrepancies were due to the absence of a bare ground control point at one site and at both steep upland limits and an abrupt gradation into the forest.

\subsection{New Marsh Boundary Differences to Current Provincial Maps}

When we compared the polygons representing salt marsh in our GIS vector layer to the current provincial ones, we found that our polygons better reflected the actual shape and size of the vegetated marsh. Extracting the marsh area from LiDAR DEMs tended to produce marsh maps that closely reflected the area of the vegetated marsh area while excluding tidal channels and some pools. In general, this resulted in many of the newly produced marsh polygons being smaller than those from the current provincial database. As the number of salt marshes along the coast of New Brunswick is too large for a comprehensive individual comparison, we instead compared our validation sites and a selected subset of marshes as examples. The validation sites were found to have a mean ratio between the new and provincial polygon areas of $0.87 \pm 0.16$ (Table 1 ). Two of the twelve validation sites had ratios above 1 , while the others were all below 1 . Two validation sites could not be properly mapped due to issues with LiDAR returns over adjacent coastal water and were excluded from the comparison (Table 1).

The DEM-produced polygons give a total area of 12,297 ha (excluding 530 ha of marsh within a national park not included in provincial maps) compared to the provincial layers' total area of 12,827 ha. If additional areas are excluded, the area of the new marsh layer is $\sim 621$ ha smaller than the current provincial layer. Only 9020 ha is consistent between the two layers, which means $\sim 30 \%$ of the area has changed between the two layers. This 
further supports our visual observations that there are large differences in shape between the new and old polygons.

New Brunswick's provincial salt marsh maps often included water and mudflat area as part of the marsh. Figure 3 shows a notable contrast between our marsh polygons and provincial polygons for a marsh near Bayfield, New Brunswick. The provincial polygons indicate the area of the southern half of the marsh in Figure 3b is 106 ha, whereas our polygons in Figure $3 \mathrm{~b}$ give an area of 61 ha; the new:old ratio is 0.58 .
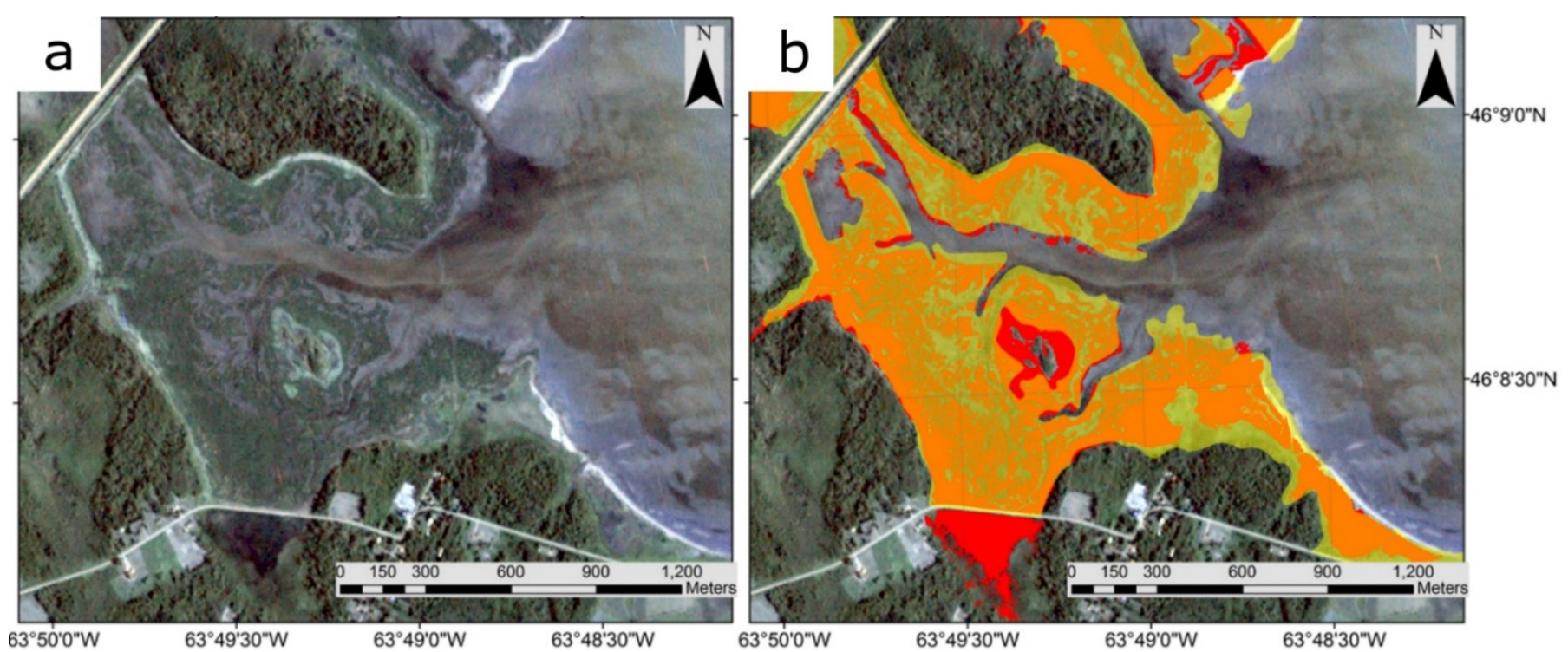

$63^{\circ} 50^{\prime} 0^{\prime \prime} \mathrm{W}$

$63^{\circ} 49^{\prime} 30^{\prime \prime} \mathrm{W}$

$63^{\circ} 49^{\prime} 0 " \mathrm{~W}$

$63^{\circ} 48^{\prime} 30^{\prime \prime} \mathrm{W}$

$63^{\circ} 50^{\prime} 0^{\prime \prime} \mathrm{W}$

$63^{\circ} 49^{\prime} 30^{\prime \prime} \mathrm{W}$

$63^{\circ} 48^{\prime} 30^{\prime \prime} \mathrm{W}$

Figure 3. A salt marsh near Bayfield, NB, on the Gulf of St. Lawrence. (a) Its highly fragmented and complex surface is visible in satellite imagery. (b). The marsh polygon derived from LiDAR (Red) overlain with the current provincial area (Yellow). The overlapping area is orange. The fragmented nature of the marsh platform, despite the size of marsh pools, is amplified due to the limitations of the DEM resolution. Imagery @ 2021 Planet Labs Inc.

Success in mapping marsh channels and ponds was inconsistent between marshes. For example, the new polygon at the Bayfield marsh (Figure $3 b$ ) included many small ponds as vegetated marsh. Visual inspection of some sites suggested that pools further from the marsh lower bounds tended to be mapped as marsh areas more often, but there was generally high variability in pool mapping.

Tidal creeks tended to only be excluded from the extracted marsh area if their width was at least $2-3 \mathrm{~m}$. Rarely, the extracted marsh area would also include adjacent creeks and rivers as being part of the marsh platform, even when quite wide. This tended to occur in isolated instances along the coast, typically affecting only single DEM tiles. The effect made it difficult or impossible to delineate the lower bounds in effected DEM tiles. The worst instances would have required significant manual redrawing of the marsh areas to fix, as the area between marshes (i.e., marshes fringing both sides of a river channel) would be mapped, resulting in merging many separate marshes into a singular polygon. As significant manual redrawing would largely defeat the purpose of extracting the marsh area from LiDAR, in the most severe cases, the provincial polygons were retained rather than redrawing.

LiDAR returns for the tidal rivers and streams of some $1 \times 1 \mathrm{~km}$ LiDAR point clouds tiles were close to or above marsh surface elevations of adjacent LiDAR point cloud tiles. The adjacent tiles sometimes showed more than $10 \mathrm{~cm}$ in vertical difference in the river elevations, suggesting those points may have been collected at different times (and thus tidal heights). Extrapolated over a $10 \times 10 \mathrm{~km}$ DEM tile, this appears to have led to sections of tidal channels and rivers within a single DEM tile to vary in elevation over the channel's length. This was most evident in a hillshaded DEM, where abrupt elevation changes in the center of a river channel caused a cliff-like feature to appear (Figure 4). As a result, 
this form of error appears to be due to some of the LiDAR being flown at or near high tide where water levels in the channel are close to (or even above if during spring tides) the elevation of the marsh lower bounds.

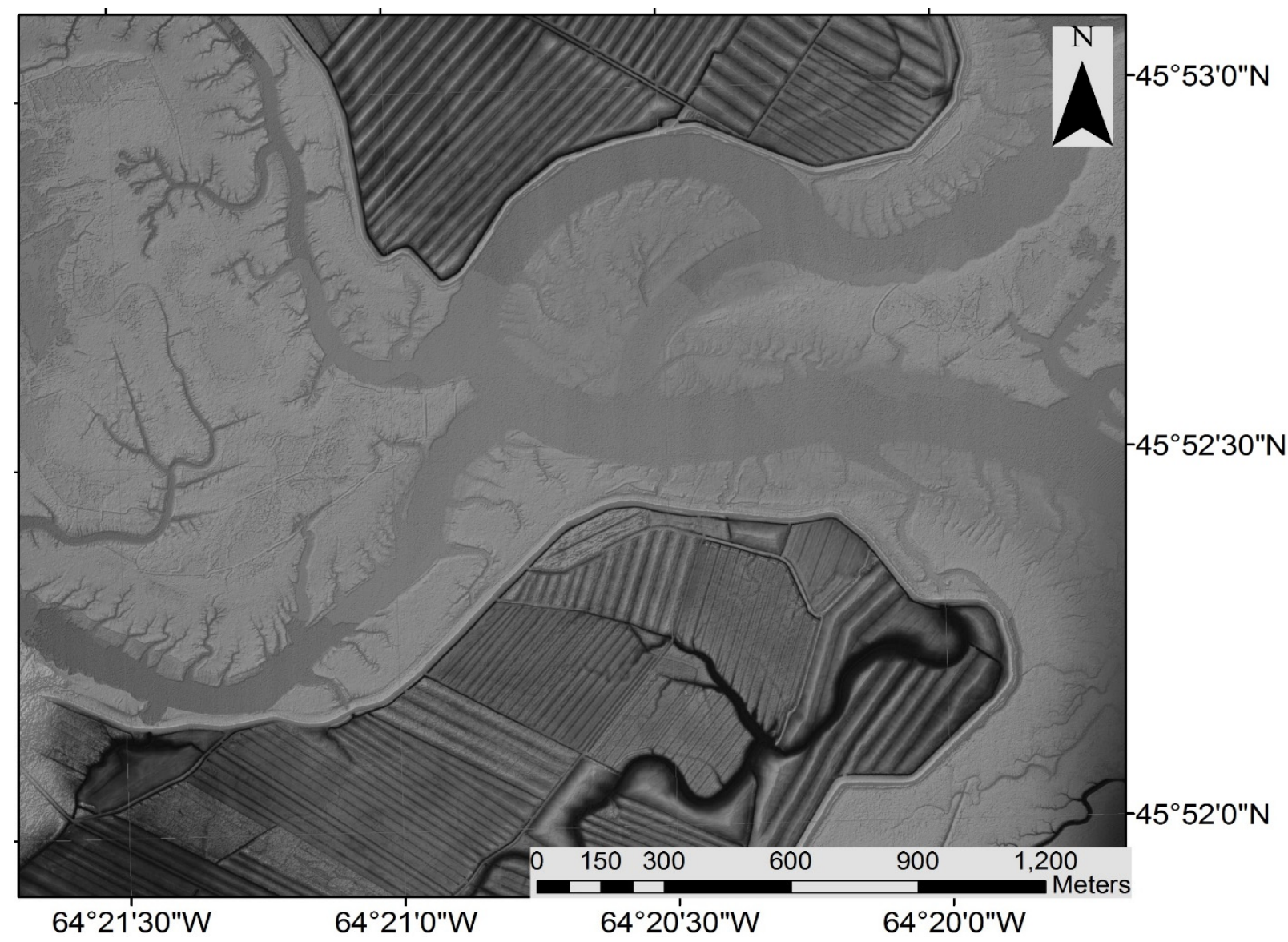

Figure 4. Example of a DEM hillshade where creek heights varied over a single DEM tile. The area designated by a black box shows where there is an abrupt change in elevation of the tidal channel. This inconsistency of channel elevations within a single DEM tile makes mapping marsh lower bounds difficult. DEM Source: GeoNB.

The use of LiDAR DEMs effectively excluded terrestrial upland areas contained within salt marshes, while provincial maps sometimes included them, resulting in the overestimation of marsh area in the latter. Figure 5 shows an example where a new marsh polygon provided an area of 23 ha versus the 36 ha for the provincial one-a ratio of 0.63 .

Our method also identified marsh areas that were not included in the provincial maps (beyond the National Park areas that were excluded). The LiDAR DEMs were sensitive enough to reveal narrow marshes fringing estuary channels and back barrier marshes. Figure 6 shows an example where a large marsh complex on the "inner" side of a barrier beach had not been mapped in its entirety. The newly mapped area in Figure 5 accounts for $\sim 45$ ha of the additional marsh area. 

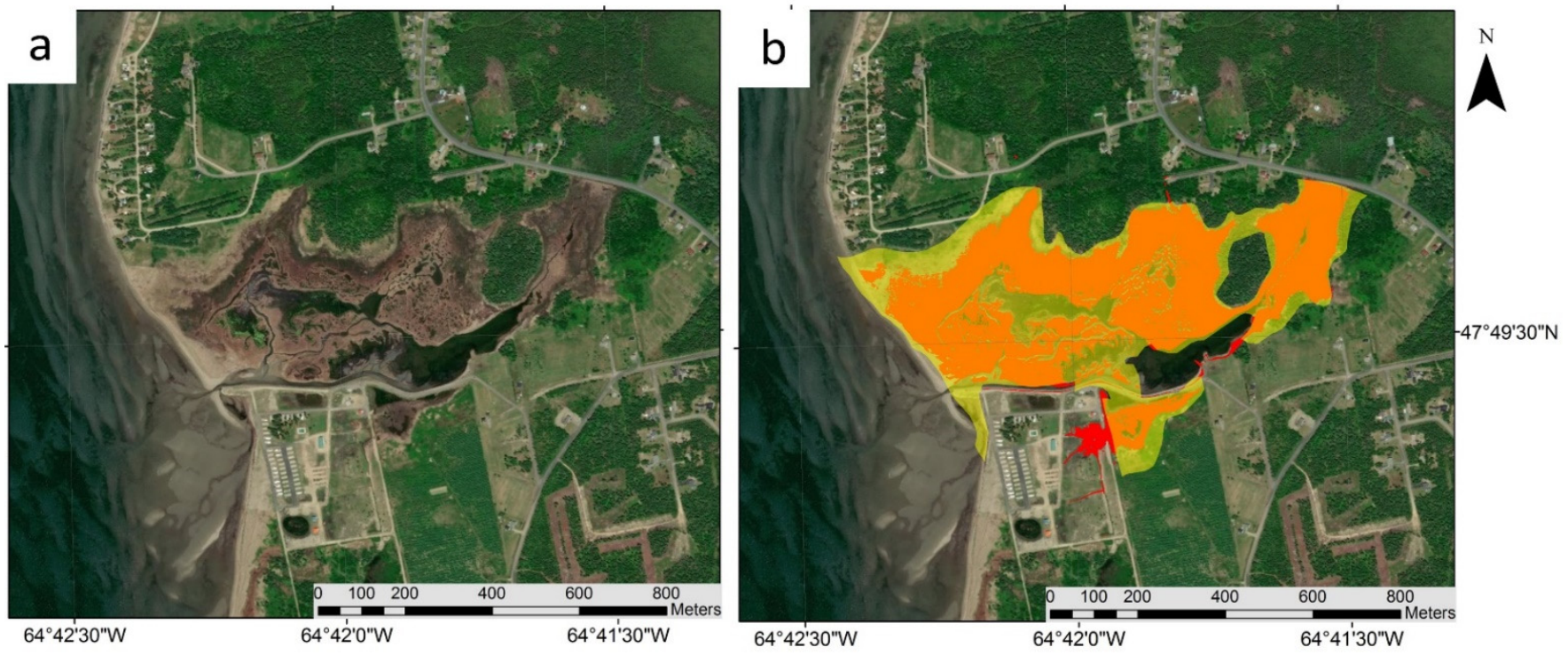

Figure 5. Pointe-Canot marsh on the Gulf of St. Lawrence: (a) satellite imagery without polygon overlay; (b) with the provincial and new marsh polygons overlain. Yellow corresponds to areas where the current provincial polygon indicates marsh presence, but the new polygon does not. Orange indicates areas where the new polygons and provincial polygons overlap. Red areas, present near the center bottom of $(\mathbf{b})$, is area mapped as marsh by the new polygon that was not included by the provincial polygon. Imagery @ 2021 ESRI.

Some marsh morphologies were not represented well in the LiDAR, however. This tended to occur where tidal access to a lagoon fringed by salt marsh is restricted (Figure 7). The polygons we extracted for this type of morphology almost always resulted in the interior water included as part of the marsh, whereas the provincial polygons often excluded the pool. These errors were not fixed, as they would require extensive manual tracing to fix, which would defeat the purpose of this study. The examination of LiDAR DEMs using a hillshade filter revealed no obvious interpolation issues (i.e., large triangles or distorted blocks of consistent elevation, suggesting interpolation from LiDAR point cloud to DEM was conducted with few points due to their being a small number of LiDAR points over a calm water body from attenuation) that may have led to this error. Thus, this is likely caused by the water level (and thus adjacent marsh) being perched above low tide elevations due to restricted outflow of water (i.e., the outlet channel in Figure 7a is blocked by sand at low tide).

Despite cleaning efforts, where the adjacent inland had a low slope, the terrestrial border tended to be very irregular (Figure 8). The steeper the terrain of the terrestrial border, the more distinct was the border. This phenomenon is likely due to the vertical error in the LiDAR DEMs. The difference between adjacent pixels mapped as terrestrial versus marsh may differ by a few centimeters or less in low relief terrain, which is far smaller than the LiDAR vertical error. Thus, the elevation in a low relief marsh may only change by a few centimeters over many meters of horizontal distance inland, which means errors in a vertical distance of more than several centimeters can cause a terrestrial pixel to be mapped as marsh and vice-versa. While the use of a minimum mapping unit did remove most of the non-marsh area, it did not fix marsh areas that may have been excluded by the same effect. For larger projects, or those carried out by individuals without local knowledge, an automated process could be employed to remove narrow polygons (e.g., $2 \mathrm{~m}$ ) that connect wider polygons. This same type of automation could be used to remove beaches that also will be picked up by the LiDAR method. 


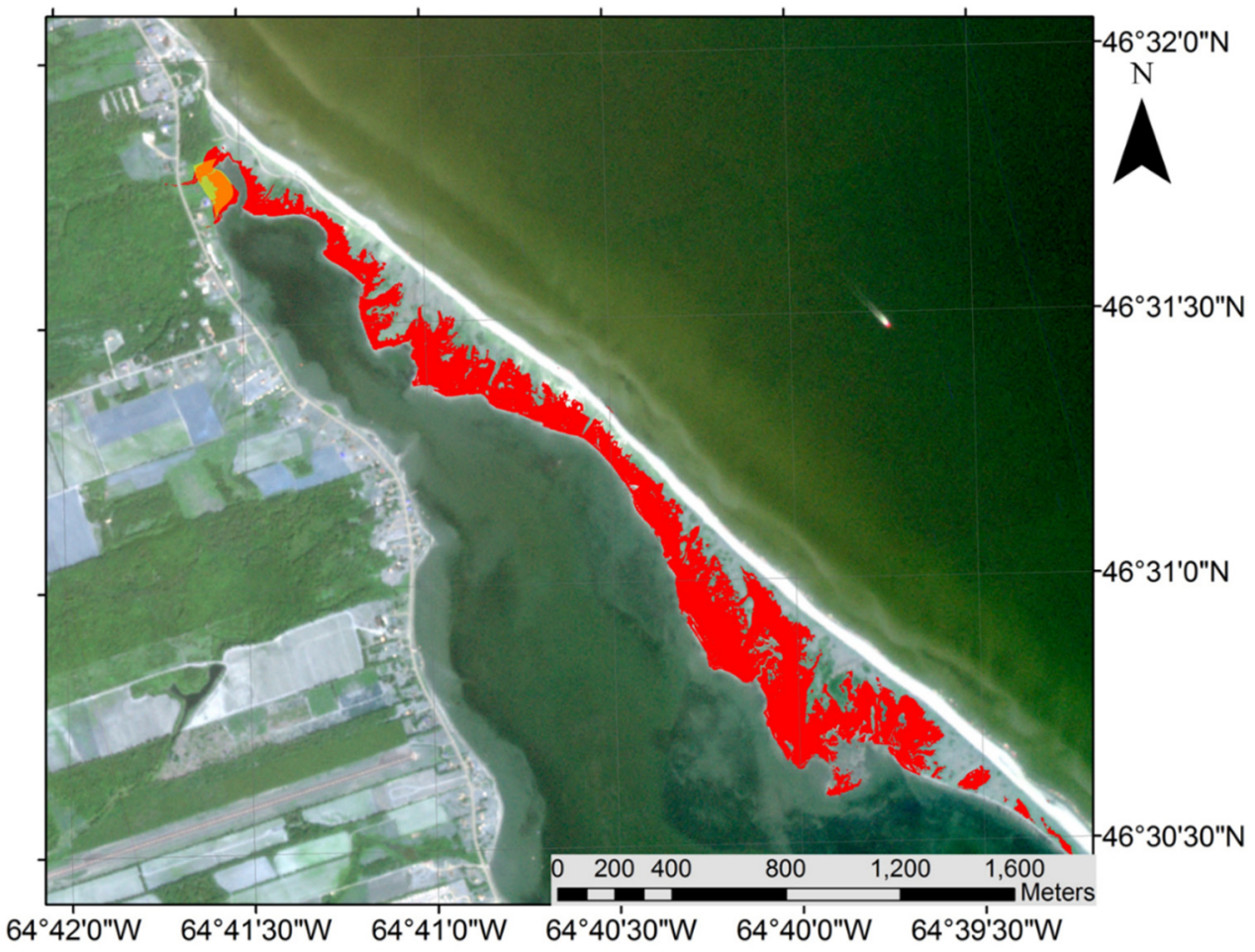

Figure 6. An example of a previously unmapped area. The small yellow area in the top left of the map corresponds to the area mapped in the provincial polygons (orange where there is overlap). The red area behind the sand spit is the newly mapped area. Imagery (C) 2021 Planet Labs Inc.

a

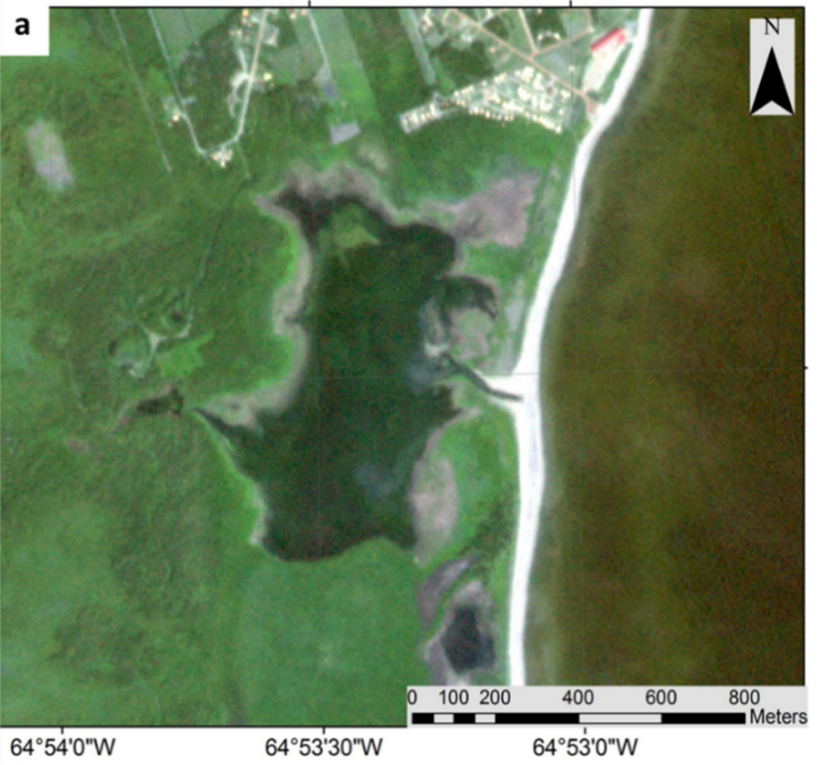

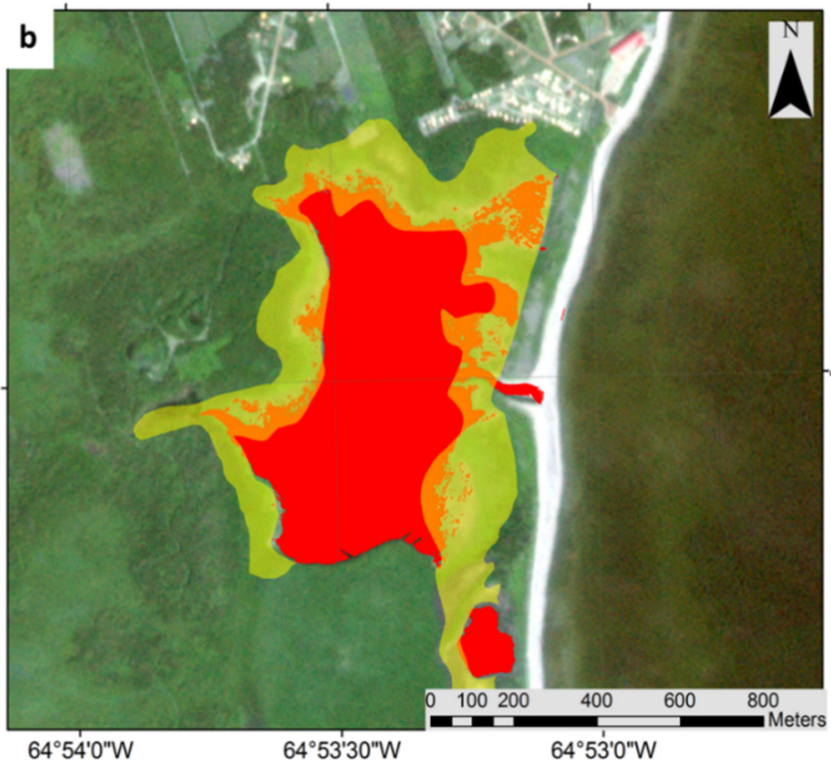

$47^{\circ} 26^{\prime} 30^{\prime \prime} \wedge$

Figure 7. Marsh just south of Val-Comeau on the Gulf of St. Lawrence. (a) Restricted tidal access and a large interior pool are visible on satellite imagery. (b) Marsh with polygon overlay. The transparent yellow indicates the area covered by provincial polygons that do not overlap with the new polygons. The solid orange color indicates where there is overlap between the two polygons (and is thus located between the transparent yellow and the red areas). Red indicates the area mapped in the new polygons which were not previously mapped. Note how the large interior pool is designated as salt marsh in the LiDAR-derived polygon, but not the provincial polygon. Imagery @ 2021 Planet Labs Inc. 


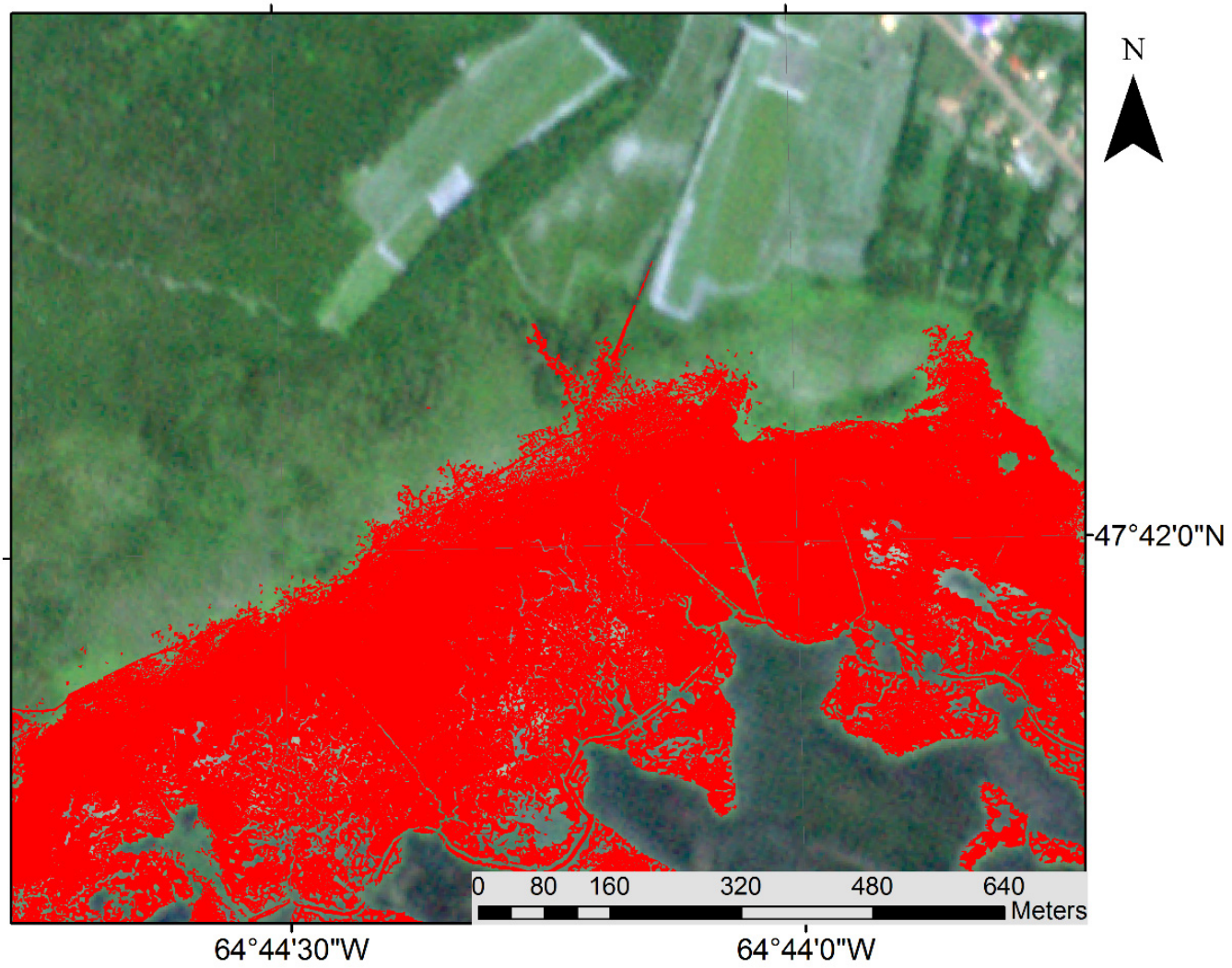

Figure 8. Marsh upland limit affected by inland patches mapped as marsh and an irregular marsh terrestrial border. While the implementation of a minimum mapping unit removed most small interior polygons, the upland border is still highly irregular. Imagery @ 2021 Planet Labs Inc.

\section{Discussion}

The quality of maps prepared with LiDAR depends upon the quality of the input data, and we found some errors in tidal data and artifacts in the LiDAR DEMs that added challenges to the mapping. In cases where tidal data were not reliable, mapping using LiDAR elevation ranges alone becomes largely unfeasible. In our experience, tidal data problems resulted in whole portions of the coastline having no apparent marsh area because the highest astronomical tide was depicted lower than the lowest DEM elevations recorded for the marsh area. There is little recourse in such cases outside having GNSS delineation of marsh bounds and/or using high-resolution multi- or hyperspectral imagery of the coast to visually define marsh area and using that to extract elevation limits from the DEMs. However, the accuracy of delineation of upland borders suffers as the extrapolation of values from sample marshes over longer coastlines may miss variability in tidal ranges.

Artifacts and inconsistencies in the LiDAR DEMs proved to cause inconsistent mapping among sections of coastlines, mostly in systems where marshes fringe a river, but also in cases where there were high LiDAR returns for coastal waters. These issues were not unexpected, as previous studies have shown elevation inconsistencies for DEMs covering salt marshes and ameliorated these through the use of elevation offsets derived from GNSS field surveys [24-26]. Often, a filter was used on the DEM using the GNSS offsets, though this can lead to the loss or smoothing of marsh topographic features [25] - a problem when attempting to accurately map marsh area. While filtering may work for individual marshes and short lengths of coastline, the large area covered in this study limited the number of surveys we could perform due to time and cost concerns. For this reason, we simply adjusted the elevations by the offsets rather than try and filter the DEM tiles.

The mean and range of elevation offsets between our field survey data and DEM elevations were similar to the range of offsets reported elsewhere [24-26], from 7 to $55 \mathrm{~cm}$. This similarity suggests that the wide-scale application of offset values for sections of 
coastlines can be sufficient for large-scale mapping. However, we note that we only surveyed the upper marsh bounds, which typically contained the tallest vegetation. The elevation offset has been found to vary with vegetation zone in other marshes, with taller vegetation tending to give a greater offset but most short vegetation giving offsets below that of the native LiDAR vertical error [25]. Offsets as high as $50 \mathrm{~cm}$ have been reported for very tall vegetation [25], as we found at Bas-Caraquet (Table 1). Half of the 12 verification sites had mean elevation offsets $>25 \mathrm{~cm}$. The low overall mean offset in this study may thus be a result of varying vegetation density, allowing LiDAR returns closer to the ground surface at sites with lower density. These issues were partially avoided by adjusting the offset (using offsets of nearby verification sites rather than the overall mean) in cases where the upland limits in a DEM tile did not align well with satellite imagery. This suggests that the level of accuracy in the delineation of upland limits (particularly in areas of low relief where marsh transition to terrestrial upland is very gradual) is likely to vary due to site variability in vegetation density and height even within a single DEM tile. Despite these issues, if the vegetation in the marsh fringe is consistent among marshes, mapping accuracy may still be maintained as the mean errors are close to the native LiDAR vertical error.

The timing of LiDAR flights is essential for accurate mapping of salt marsh area (to properly extract the marsh lower bounds) using LiDAR DEMs, though the method presented here could still be used to delineate the upland limits of the marshes that would be largely unaffected. We found that, in some DEM tiles, LiDAR returns in tidal channels and rivers showed returns similar to the marsh platform elevation. As there was no consistent evidence of LiDAR attenuation causing low numbers of returns, it is likely that some of the LiDAR data were flown during high tide. The collection of LiDAR data during high tide is problematic as the water level may be close to or at the elevation of the marsh platform. The use of high resolution $(\leq 3 \mathrm{~m})$ multispectral imagery to classify and remove water features is a possible solution but requires additional processing and access to such imagery for large areas, despite some issues with determining precise flight timing.

Marshes with restricted tidal connections appeared to have different elevation ranges than marshes nearby within the same DEM tile, typically manifesting as large interior pools mapped as marsh. Our observations suggest this is the result of restricted drainage during low tide. Such systems maintain a minimum level of water even at low tide, causing marsh elevations to be restricted to a narrower range. In cases where this standing water is at an elevation near or above the MWL, then any open water area of the marsh would be mapped as a marsh platform.

A limitation to LiDAR mapping of marshes we observed is the variable exclusion or inclusion of marsh pools and tidal channels along the coast. This is consistent with observations that LiDAR is not good at consistently resolving marsh microtopography [25], which is largely attributable to difficulty in obtaining true ground return and because many features are smaller than the DEM pixel resolution and get smoothed out. While the extraction of tidal creek networks from LiDAR has been performed for individual marshes [22], the significant post-processing required on a per marsh basis is not compatible with large-scale mapping. Since the extraction method we used is dependent on the elevation, whether a pool or tidal channel is mapped as marsh or excluded is largely dependent on its width and depth. If the feature is lower than MHW and $>1 \mathrm{~m}^{2}$ in size, it was generally excluded from the marsh polygon. A further complication, however, is that the pools may have algae floating on the surface that can reflect the LiDAR laser, causing the pools to appear at an elevation similar to the marsh platform. Since pools within a single marsh can also be variably drained (and thus may show differing elevations), it is not uncommon to have marsh polygons where only a portion of the pools are excluded. Where relief tends to be high between pools and the marsh platform and the pool features were large, nearly all the pools and channels can be excluded, but this was very rare. Thus, the use of LiDAR DEMs and elevation alone cannot effectively exclude small-scale non-marsh 
features but is generally successful in excluding larger ones and maintaining an accurate marsh shape.

Mapping of salt marsh and other coastal features using LiDAR has been performed previously e.g., [18-20,22,23,30,31], though these studies largely involve mapping individual marshes and not large areas. While they analyze a much smaller area, this allows for the use of more complex mapping procedures that provide some insight into how some of the challenges encountered in our study could be overcome. Such uses include extracting legal shoreline boundaries [30], mapping marsh tidal creek networks [22] and using LiDAR in conjunction with other remote sensing data, such as multi- and hyperspectral imagery [18,20,22,23], among others.

Fundamentally, the extraction of a coastline using LiDAR [30] is similar in methodology to what we performed here, the main difference being the need to extract both upper and lower bounds in our study. The mapping of the US coastline using LiDAR included a hydrodynamic modeling component that was used to estimate the variance in tidal ranges along the coastline to ensure a high tidal data accuracy [30]. Such modeling could solve many of the problems encountered with tidal data in our project; however, the method would require data that are not necessarily broadly available and require a notable increase in computation resources and time. Combining LiDAR with satellite imagery has been shown to be able to produce highly accurate wetland area and vegetation zonation (>85\% accuracy in mapping vegetation zonation within salt marsh) $[20,31]$. Accurately mapping wetland vegetation zones will, in turn, allow one to accurately map the marsh boundaries, though this method does require more processing time and resources versus using only LiDAR as extremely high-resolution multi- or hyperspectral imagery ( $\geq 3 \mathrm{~m}$ pixel resolution) would be required to provide the same level of marsh boundary precision as in our project.

One area where improvements in marsh area mapping may be made is in better delineation of tidal creek networks and pools, which were inconsistent in our study. By combining slope and elevation data with tidal data, tidal creek networks can be extracted for individual wetlands using a semi-automated GIS extraction process and image postprocessing methods [22]. We used a similar method in ours. While the methods tended to underestimate the area of narrow terminal channels due to the nature of the image post-processing used to connect gaps in the creek network extraction caused by vegetation covering the creek [22], it would likely still improve marsh area estimates if the full tidal creek network could be excluded. It should also be possible to detect and exclude pools in the marsh using a similar method. While such a method would be the easiest to implement on the large scale of mapping in our study, the analysis time would be much higher unless the method could be fully automated.

The methods used in our study can accurately exclude large non-marsh features and provide accurate marsh areas, thus enabling relatively quick and easy estimation of salt marsh soil carbon stocks (i.e., blue carbon) over large areas, particularly if there is knowledge of marsh soil depths and geomorphological configuration [32]. The lack of both complete and accurate mapping for salt marsh and many other types of wetlands has consistently been a factor limiting the accuracy of large-scale (province/state, country, and global) C stock or emission estimates e.g., $[33,34]$. The use of LiDAR to map salt marsh and other wetlands is thus an important tool to improve modeling efforts for both salt marsh and other wetlands that could be more easily mapped through the use of LiDAR.

While other wetland mapping studies utilizing LiDAR allow for more precise mapping, in some cases, such as mapping individual vegetation zones within a wetland, their methods are technically complex, require acquired data at a potentially high cost and could be very time-consuming to scale to the level of an entire province. If one is to map the area of many tidal wetlands, complex mapping may be unnecessarily costly, both in time and monetary resources. In contrast, the method in our study allows for large-scale mapping of tidal wetlands along extensive coastlines using primarily a single imagery source (LiDAR) that is readily scalable to any area. This potentially allows for tidal wetland maps of 
entire coastlines to be updated more often (subject to LiDAR flight periodicity) to track changes in size and shape of wetlands in response to climate change, rising sea levels and anthropogenic disturbance. These methods could also be used to project future wetland areas and available marsh migration space by adding the expected rates of sea-level rise to the marsh upper bounds during extraction, thus aiding plans for adaptation to climate change.

\section{Conclusions}

The challenges and limitations of our LiDAR application mostly affect the delineation of the marsh lower bounds and the interior of the marsh. In cases where LiDAR was flown near high tide, the marsh's lower limits were subjected to problems with extraction, and this caused high variability for the lower bounds, even in a single LiDAR DEM tile. Marsh interior features, such as tidal creeks and ponds, were inconsistently mapped due to inadequate LiDAR pixel resolution and difficulties with receiving true ground returns through dense vegetation. The delineation of the upland limit, however, was largely unaffected by any problems beyond some uncertainty due to highly variable vegetation heights between marshes. Since the mean elevation offset between GNSS and DEM elevations was from a diverse set of validation sites, the offsets used in this study are considered acceptable for large-scale mapping. Furthermore, the correction of the output from this study could be performed if desired, as creeks, ponds, unvegetated tidal flats and open water are easily visible in aerial photographs and satellite imagery with the appropriate spatial resolutions. Additionally, since recognition of these features does not require familiarity with regional vegetation, they can be easily delineated without specialized botanical knowledge or mapping of vegetation.

As salt marsh taxa are unlikely to be present to any significant degree above HAT, the limit extracted from this technique is likely to be highly accurate (within the quality of the data used). In general, visual inspection with satellite data supports this. Thus, LiDAR can successfully be used to map the upper boundary of salt marshes without the need to first delineate individual plant species. Extracting marsh areas from LiDAR can be applied to update and correct existing salt marsh maps along extensive lengths of coastlines in less time than required to manually trace from imagery. The use of a quantitative limit also allows for more consistency in large-scale mapping, where mapping of marsh limits may be performed by multiple individuals who may differ in their interpretation of imagery. In our project, the new polygons better depicted the shape and size of the marsh platform and marsh upper limit than those previously available for the coastlines we mapped, despite inconsistencies with creek and pool mapping, as some provincial polygons included significant areas of open water within their bounds.

The use of LiDAR to map inland salt marsh boundaries has important applications in assessing the value of salt marshes with respect to carbon credits. Carbon crediting projects require the assessment of permanence of a project over 100 years. The LiDAR data can be used to project the future upland edge of the marsh under multiple scenarios of rising sea levels. As mapping salt marsh with LiDAR excludes many channels and ponds while generally providing more accurate marsh shape and area, this mapping approach would be useful in determining areas upon which to calculate blue carbon stocks and accumulation rates for a marsh or an entire region.

Author Contributions: Formal analysis, L.B.v.A.; conceptualization L.B.v.A. and G.L.C.; methodology, validation and analyses-L.B.v.A.; writing, review and editing-L.B.v.A. and G.L.C.; project administration-G.L.C.; funding acquisition-G.L.C. All authors have read and agreed to the published version of the manuscript.

Funding: This research was funded by THE NEW BRUNSWICK ENVIRONMENTAL TRUST FUND, Project No. 190150 and NSERC AWARD No 105665-2013.

Data Availability Statement: Not applicable. 
Acknowledgments: We would like to thank the Canadian Hydrographic Service for providing tide level data for the NB coastline and Margaret Kalacska for providing comments on the manuscript.

Conflicts of Interest: The authors declare no conflict of interest. The funders had no role in the design of the study; in the collection, analyses, or interpretation of data; in the writing of the manuscript, or in the decision to publish the results.

\section{References}

1. Koch, E.W.; Barbier, E.B.; Silliman, B.R.; Reed, D.J.; Perillo, G.M.E.; Hacker, S.D.; Granek, E.F.; Primavera, J.H.; Muthiga, N.; Polasky, S.; et al. Non-linearity in ecosystem services: Temporal and spatial variability in coastal protection. Front. Ecol. Environ. 2009, 7, 29-37. [CrossRef]

2. Nordlie, F.G. Fish communities of estuarine salt marshes of eastern North America, and comparisons with temperate estuaries of other continents. Rev. Fish Biol. Fish. 2003, 13, 281-325. [CrossRef]

3. Barbier, E.B.; Koch, E.W.; Silliman, B.R.; Hacker, S.R.; Wolanski, E.; Primavera, J.; Granek, E.F.; Polasky, S.; Aswani, S.; Cramer, L.A.; et al. Coastal ecosystem-based management with Nonlinear Ecological functions and values. Science 2008, 319, 321-323. [CrossRef]

4. Morgan, P.A.; Burdick, D.M.; Short, F.T. The functions and values of fringing salt marshes in northern New England, USA. Estuaries Coasts 2009, 32, 483-495. [CrossRef]

5. Macreadie, P.I.; Anton, A.; Raven, J.A.; Beaumont, N.; Connolly, R.M.; Friess, D.; Kelleway, J.; Kennedy, H.; Kuwae, T.; Lavery, P.S.; et al. The future of blue carbon science. Nat. Commun. 2019, 10, 3998. [CrossRef]

6. Mcleod, E.; Chmura, G.L.; Björk, M.; Bouillon, S.; Duarte, C.M.; Lovelock, C.; Salm, R.; Schlesinger, W.; Silliman, B. A Blueprint for blue carbon: Towards an improved understanding of the role of vegetated coastal habitats in sequestering $\mathrm{CO}_{2}$. Front. Ecol. Environ. 2011, 9, 552-560. [CrossRef]

7. Adam, P. Saltmarshes in a time of change. Environ. Conserv. 2002, 29, 39-61. [CrossRef]

8. Foster, N.M.; Hudson, M.D.; Bray, S.; Nicholls, R.J. Intertidal mudflat and saltmarsh conservation and sustainable use in the UK: A review. J. Environ. Manag. 2013, 126, 96-104. [CrossRef] [PubMed]

9. Chmura, G.L. What do we need to assess the sustainability of the tidal salt marsh carbon sink? Ocean Coast. Manag. 2013, 83, 25-31. [CrossRef]

10. Jacobson, H.A.; Jacobson, G.L.; Kelley, J.T. Distribution and abundance of tidal marshes along the coast of Maine. Estuaries 1987, 10, 126-131. [CrossRef]

11. Brown, W.W. Wetland mapping in New Jersey and New York. Photogramm. Eng. Remote Sens. 1978, 44, 303-314.

12. Allen, J.R.L. Morphodynamics of Holocene salt marshes: A review sketch from the Atlantic and Southern North Sea coasts of Europe. Quat. Sci. Rev. 2000, 19, 1155-1231. [CrossRef]

13. Suchrow, S.; Jensen, K. Plant species responses to an elevational gradient in German North Sea salt marshes. Wetlands 2010, 30, 735-746. [CrossRef]

14. Moeslund, J.E.; Arge, L.; Bocher, P.K.; Nygaard, B.; Svenning, J.C. Geographically comprehensive assessment of salt-meadow vegetation-elevation relations using LiDAR. Wetlands 2011, 31, 471-482. [CrossRef]

15. Bertness, M.D. Zonation of Spartina patens and Spartina alterniflora in a New England salt marsh. Ecology 1991, 72, 138-148. [CrossRef]

16. Pavri, F.; Dailey, A.; Valentine, V. Integrating multispectral ASTER and lidar data to characterize coastal wetland landscapes in the northeastern United States. Geocarto Int. 2011, 26, 647-661. [CrossRef]

17. Feagin, R.A.; Martinez, M.L.; Mendoza-Gonzalez, G.; Costanza, R. Salt marsh zonal migration and ecosystem service change in response to global sea level rise: A case study from an urban region. Ecol. Soc. 2010, 15, 14. Available online: http://www.ecologyandsociety.org/vol15/iss4/art14/ (accessed on 16 October 2021). [CrossRef]

18. Chust, G.; Galparsoro, I.; Borja, A.; Franco, J.; Uriarte, A. Coastal and estuarine habitat mapping, using LIDAR height and intensity and multi-spectral imagery. Estuar. Coast. Shelf Sci. 2008, 78, 633-643. [CrossRef]

19. Collin, A.; Long, B.; Archambault, P. Salt-marsh characterization, zonation assessment, and mapping though a dual-wavelength LiDAR. Remote Sens. Environ. 2010, 114, 520-530. [CrossRef]

20. Rapinel, S.; Hubert-Moy, L.; Clement, B. Combined use of lidar and multispectral earth observation imagery for wetland habitat mapping. Int. J. Appl. Earth Obs. Geoinf. 2015, 37, 56-64. [CrossRef]

21. Rosso, P.H.; Ustin, S.L.; Hastings, A. Use of lidar to study changes associated with Spartina invasion in San Francisco Bay marshes. Remote. Sens. Environ. 2006, 100, 295-306. [CrossRef]

22. Chirol, C.; Haigh, I.D.; Pontee, N.; Thompson, C.E.; Gallop, S.L. Parameterizing tidal creek morphology in mature saltmarshes using semi-automated extraction from lidar. Remote Sens. Environ. 2018, 209, 291-311. [CrossRef]

23. Kulawardhana, R.W.; Popescu, S.C.; Feagin, R.A. Fusion of lidar and multispectral data to quantify salt marsh carbon stocks. Remote Sens. Environ. 2014, 154, 345-357. [CrossRef]

24. Montané, J.M.; Torres, R. Accuracy assessment of Lidar saltmarsh topographic data using RTK GPS. Photogramm. Eng. Remote Sens. 2006, 72, 961-967. [CrossRef]

25. Chassereau, J.E.; Bell, J.M.; Torres, R. A comparison of GPS and Lidar salt marsh DEMs. Earth Surf. Process Landf. 2011, 36, 1770-1775. [CrossRef] 
26. Hladik, C.; Alber, M. Accuracy assessment and correction of a LIDAR-derived salt marsh digital elevation model. Remote Sens. Environ. 2012, 121, 224-235. [CrossRef]

27. Rogers, J.N.; Parrish, C.E.; Ward, L.G.; Burdick, D.M. Assessment of elevation uncertainty in salt marsh environments using discrete-return and full-waveform lidar. J. Coast. Res. 2016, 76, 107-122. [CrossRef]

28. GeoNB. LiDAR Derived Digital Elevation Models. 2019. Available online: http://geonb.snb.ca/nbdem/ (accessed on 16 October 2021).

29. Natural Resources Canada. Precise Point Positioning. 2019. Available online: https://webapp.geod.nrcan.gc.ca/geod/toolsoutils/ppp.php (accessed on 16 October 2021).

30. White, S. Utilization of LIDAR and NOAA's Vertical Datum Transformation Tool (VDatum) for Shoreline Delineation. OCEANS 2007, 2007. [CrossRef]

31. Bertels, L.; Houthuys, R.; Sterckx, S.; Knaeps, E.; Deronde, B. Large-scale mapping of the riverbanks, mud flats and salt marshes of the Scheldt basin, using airborne imaging spectroscopy and LiDAR. Int. J. Remote Sens. 2011, 32, 2905-2918. [CrossRef]

32. Van Ardenne, L.B.; Jolicouer, S.; Berube, D.; Burdick, D.; Chmura, G.L. The importance of geomorphic context for estimating the carbon stock of salt marshes. Geoderma 2017, 330, 264-275. [CrossRef]

33. Bridgham, S.D.; Megonigal, J.P.; Keller, J.K.; Bliss, N.B.; Trettin, C. The carbon balance of North American wetlands. Wetlands 2006, 26, 889-916. [CrossRef]

34. Pendleton, L.; Donato, D.C.; Murray, B.C.; Crooks, S.; Jenkins, W.A.; Sifleet, S.; Craft, C.; Fourqurean, J.W.; Kauffman, J.B.; Marba, N.; et al. Estimating global "blue carbon" emissions from conversion and degradation of vegetated coastal ecosystems. PLOS ONE 2012, 7, e43542. 